\title{
Improved Methods of Solutions to Problems in Chemistry
}

\author{
R. Subramanya \\ Chief Pharmacist, Cheluvamba Hospital, Mysore, India-570 001
}

\begin{abstract}
This is a review article with advanced methods of calculations that helps the students to solve problems of chemistry. It cuts down the number of steps in many solutions given in books. Algebraic method furnished in this article for balancing chemical equations, brings down the stress that the students usually experience while solving such problems. Links between Molarity, Molality and Mole fraction are established. This helps the students to understand the concepts of Molarity, Molality and Mole fraction and shows that they are same but understood with respect to different radices. Many steps appear as practical, easily understandable and maintain good relationship between the steps. A new idea is proposed on density at section 4 of this article. This density seems to be more stable than the prevailing concept of density. Most of the problems of chemistry look arithmetical; here it is made to look more algebraic. Problem on percentage composition is solved using determinant method.
\end{abstract}

Keywords: Density, Molarity, Percentage, composition. Algebraic.

\section{Introduction}

Before going through this article, reading [1] is very essential.

Algebraic method of balancing equations that are given in section -2 of this article will bring down the mental stress of solvers of such problems.

At section 3.03 while finding molecular formula of a compound quantity of oxygen is directly and proportionately deducted as usually done in algebraic equations.

At section- 6, maximum density of water that it can have, if removable space available between the water molecules are removed, is deduced.

At section 7.00 while solving problem on percentage composition, determinant method is used.

In section 8 , relation between molarity, molality and mole fraction are established at a single stretch.

A relation is furnished for direct conversion of percentage expression to molrity at section 8.04

Solution to the problem at section 8.11 found through a new route. Here density is mainly used to find the molarity and molality.

Problem on dimensional analysis at section.9.02. Solved directly using the radix L (liter). This concept will be very helpful to the students while solving such problems.

To the problem 9.03, result found by dimensional analysis whit in a few steps

\section{Balancing Chemical Equations algebraically. (Whose total mass is conserved)}

Example-1: Consider an unbalanced chemical equation; $\mathrm{CH}_{4}+\mathrm{O}_{2} \rightarrow \mathrm{CO}_{2}+\mathrm{H}_{2} \mathrm{O}$

Let a,b,c,d be the required coefficients of components of reactants and products. Then this equation can be written as,

$: a\left(\mathrm{CH}_{4}\right)+b\left(\mathrm{O}_{2}\right) \rightarrow c\left(\mathrm{CO}_{2}\right)+d\left(\mathrm{H}_{2} \mathrm{O}\right)$

: This can be written as; $a(C)+4 a(H)+2 b(O) \rightarrow c(C)+2 c(O)+2 d(H)+d(O)---(1)$

Number of elements on both sides wil be equal, Then comparing similar components on both sides,

: we have, $a(C)=c(C)$

: Consequently, $\frac{a}{c}=\frac{1}{1}$ or $a=c=1$ (or multiple of 1 )

: Similarly, $4 a(H)=2 d(H)$

$: \frac{a}{d}=\frac{1}{2}$ and its equivalent ratio ; basically, $a=1$ and $d=2$

: And, $2 b(O)=(2 c+d)(O)$

: Hence, $b=2$

: i.e., $a=1, b=2, c=1, d=2$

Putting these values of coefficients in (1)we have,

$:(C)+4(H)+4(O) \rightarrow(C)+2(O)+4(H)+2(O)$

: rearranging as respective compounds we have, $\mathrm{CH}_{4}+2 \mathrm{O}_{2} \rightarrow \mathrm{CO}_{2}+2 \mathrm{H}_{2} \mathrm{O}$

Thus the equation is balanced. 
Example 2: $\mathrm{Fe}+\mathrm{H}_{2} \mathrm{SO}_{4} \rightarrow \mathrm{Fe}_{2}\left(\mathrm{SO}_{4}\right)_{3}+\mathrm{H}_{2}$

Let a,b,c,d be the required coefficients of components of reactants and products. Then this equation can be written as,

$: a(\mathrm{Fe})+b\left(\mathrm{H}_{2} \mathrm{SO}_{4}\right) \rightarrow c\left(\mathrm{Fe}_{2}\left(\mathrm{SO}_{4}\right)_{3}\right)+d\left(\mathrm{H}_{2}\right)$

$: a(F e)+2 b(H)+b(S)+4 b(O) \rightarrow 2 c(F e)+3 c(S)+12 c(O)+2 d(H)----(2)$

By comparison

$: a(F e)=2 c(F e)$

$: a=2, c=1$

$: 2 b(H)=2 d(H)$

$: b=d$

$: b(S)=3 c(S)$

$: b=3, c=1$

$: 4 b(0)=12 c(0)$

$: b=12, c=4$ or $b=3, c=1$

: Abstract of values of a,b,c,d are, $a=2, b=3, c=1, d=3$ (because $b=d$ )

$: 2(\mathrm{Fe})+6(\mathrm{H})+3(\mathrm{~S})+12(\mathrm{O}) \rightarrow 2(\mathrm{Fe})+3(\mathrm{~S})+12(\mathrm{O})+6(\mathrm{H})$

Rearranging them as their respective components, we have,

$: 2 \mathrm{Fe}+3 \mathrm{H}_{2} \mathrm{SO}_{4} \rightarrow \mathrm{Fe}_{2}\left(\mathrm{SO}_{4}\right)_{3}+3 \mathrm{H}_{2}$

Example 3: $\left(\mathrm{NH}_{4}\right)_{3} \mathrm{PO}_{4}+\mathrm{Pb}\left(\mathrm{NO}_{3}\right)_{4} \rightarrow \mathrm{Pb}_{3}\left(\mathrm{PO}_{4}\right)_{4}+\mathrm{NH}_{4} \mathrm{NO}_{3}$

Let a,b,c,d be the required coefficients of components of reactants and products. Then this equation can be written as,

$: a\left\{\left(\mathrm{NH}_{4}\right)_{3} \mathrm{PO}_{4}\right\}+b\left\{\mathrm{~Pb}\left(\mathrm{NO}_{3}\right)_{4}\right\} \rightarrow c\left\{\mathrm{~Pb}_{3}\left(\mathrm{PO}_{4}\right)_{4}\right\}+d\left\{\mathrm{NH}_{4} \mathrm{NO}_{3}\right\}$

$:\{3 a(N)+12 a(H)+a(P)+4 a(O)\}+\{b(P b)+4 b(N)+12 b(O)\}$

$\rightarrow\{3 c(P b)+4 c(P)+16 c(O)\}+\{d(N)+4 d(H)+d(N)+3 d(O)\}---(3)$

By comparison

$: 3 a(N)+4 b(N)=d(N)+d(N)$

$: 2 d=3 a+4 b$

$: 12 a(H)=4 d(H)$

$: d=12, a=4$

$: a(P)=4 c(P)$

$: a=4, c=1$

$: 4 a(0)+12 b(0)=16 c(0)+3 d(0)$

$: 4 a+12 b=16 c+3 d$

$: b(P b)=3 c(P b)$

$: b=3, c=1$

Now the values of coefficients are as following,

$: a=4, b=3, c=1, d=12$

Putting these values in (3) we have

$:\{12(N)+48(H)+4(P)+16(O)\}+\{3(P b)+12(N)+36(O)\}$

$\rightarrow\{3(P b)+4(P)+16(O)\}+\{12(N)+48(H)+12(N)+36(O)\}$

To rewrite in the form of compound, common factor is taken out, and removing plus sign, we have,

: $4\left\{\left(\mathrm{NH}_{4}\right)_{3} \mathrm{PO}_{4}\right\}+3\left\{\mathrm{~Pb}\left(\mathrm{NO}_{3}\right)_{4}\right\} \rightarrow \mathrm{Pb}_{3}\left(\mathrm{PO}_{4}\right)_{4}+12\left\{\mathrm{NH}_{4} \mathrm{NO}_{3}\right\}$

Thus equation is balanced.

\section{Molecular Formula of a compound.}

3.01. Two oxides of metal contain $27.6 \%$ and $30 . \%$ of oxygen respectively. If the formula of the first compound is $\mathrm{M}_{3} \mathrm{O}_{4}$, find the formula of the second compound. [3]

Solution:

$: M_{3} O_{4}=3(M)+4(O)$

writting them with their atomic weight or molar mass we have

$:=3 x(M)+4 \times 16(0)$

Opinion: In the book the number 64 enters suddenly without explanation. This may leads to confusion to the student. This confusion is eliminated at the initial step of this solution.

It is given that, $4(O)=27.6 \%$, when mass expressed as $\%$

: Consequently, $3 x(M)=(100-27.6) \%=72.4 \%$

: And,$(O)=6.9 \%$

:Also, $(M)=24.13 \%$

: Further,$\frac{(M)}{(O)}=\frac{24.13 \%}{6.9 \%}$ 
$: \frac{(M)}{16}=\frac{24.13 \%}{6.9 \%}$
$:(M)=16\left(\frac{24.13 \%}{6.9 \%}\right)$

When rounded off to 2 significant figures.

$:(M)=56$

Let $M_{x} O_{y}$ be the second compound, then

: Molecular wt. of $M_{x} O_{y}=x(M)+y(O)$

$: \quad=(100-30) \%$ of $M+(30 \%$ of 0$)$

Therefore, $x(M)=70 \%$

$$
=70 \%(M)+30 \%(O)
$$

And, $y(O)=30 \%$

$$
\begin{gathered}
\frac{x(M)}{y(O)}=\frac{70 \%}{30 \%} \\
\frac{x(56)}{y(16)}=\frac{70 \%}{30 \%} \\
\frac{x}{y}=\frac{7 \times 16}{3 \times 56} \\
\frac{x}{y}=\frac{2}{3}
\end{gathered}
$$

: i.e., $x=2, y=3$ or multiples of 2 and 3

Accordingly, formula of the second compound is $\mathrm{M}_{2} \mathrm{O}_{3}$

3.02. The molecular mass of an organic compound is 78 and its percentage composition is $92.4 \% \mathrm{C}$ and $7.6 \%$ H. Determine the molecular formula of the compound.[4]

Solution:

Let $x$ and $y$ be the atomicities of $C$ and $H$.

Then this compound can be written as $C_{x} H_{y}$

: Further, $C_{x} H_{y}=x(C)+y(H)$

: Given, $100 \%\left(C_{x} H_{y}\right)=92.4 \%(C)+7.6 \%(H)$

Multiplying the above equation throughout by 100 , we get, [1]

$: 100\left(C_{x} H_{y}\right)=92.4(C)+7.6(H)$

Also given that molecular mass of $\left(C_{x} H_{y}\right)$ is 78. To make the LHS of the above equation equal to 78 , it is multiplied by the factor $\frac{78}{100}$ throughout and rounding off to zero decimal place, we get,

$: 78\left(C_{x} H_{y}\right)=72(C)+6(H)$

This can also be written with their atomic mass as, $12 x(C)+y(H)=72(C)+6(H)$

: Consequently, $12 x(C)=72(C)$

: Hence, $x=6, y=6$

$$
\text { And, } y(H)=6(H)
$$

Replacing above values in the molecular formula, we get $\left(C_{x} H_{y}\right)=\left(C_{6} H_{6}\right)$

3.03. (a). Butyric acid contains only $C, H$ and $O$. A $4.24 \mathrm{mg}$ sample of butyric acid is completely burnt. It gives $8.45 \mathrm{mg}$ of carbon dioxide and $3.46 \mathrm{mg}$ of water. What is the mass percentage of each element in butyric acid?

(b) The molecular mass of butyric acid was determined by experiment to be $88 u$. What is the molecular formula?[5]

Solution:

Let $x, y, z$ be the atomicities of $C, H, O$ respectively.

Then, molecular fomula of butyric acid is $\left(\mathrm{C}_{x} \mathrm{H}_{y} \mathrm{O}_{z}\right)$

The statement, when $4.24 \mathrm{mg}$ sample of butyric acid is completely burnt, gives $8.45 \mathrm{mg}$ of carbon dioxide and $3.46 \mathrm{mg}$ of water, can be written mathematically as following.

$: 4.24 \mathrm{mg}\left(\mathrm{C}_{x} \mathrm{H}_{y} \mathrm{O}_{z}\right)+\operatorname{amg}(\mathrm{O}) \stackrel{\text { burnt }}{\longrightarrow} 8.45 \mathrm{mg}\left(\mathrm{CO}_{2}\right)+3.46 \mathrm{mg}\left(\mathrm{H}_{2} \mathrm{O}\right)---(4)$

While burning, an unknown quantity of oxygen combines with butyric acid. This unknown quantity is denoted by ' $a$ ' as coefficient of $\mathrm{O}$. The above equation will be an example to the law of conservation of mass.

Now, ' $a$ ' which is the quantity of oxygen that has combined with butyric acid will be,

$: a m g \rightarrow[8 \cdot 45 \mathrm{mg}+3 \cdot 46 \mathrm{mg}]-4 \cdot 24 \mathrm{mg}$ 
$: a m g=7 \cdot 67 m g$

Putting this value in (4) we get

$: 4 \cdot 24 \mathrm{mg}\left(\mathrm{C}_{x} \mathrm{H}_{y} \mathrm{O}_{z}\right)+7 \cdot 67 \mathrm{mg}(\mathrm{O}) \stackrel{\text { burnt }}{\longrightarrow} 8 \cdot 45 \mathrm{mg}\left(\mathrm{CO}_{2}\right)+3 \cdot 46 \mathrm{mg}\left(\mathrm{H}_{2} \mathrm{O}\right)$

To make weight of butyric acid equal to 1 molar mass, above equation is multiplied

by $\frac{88 u}{4 \cdot 24 \mathrm{mg}}$, where $88 u$ is the molar mass of the butyric acid.

:Then, $88 u\left(C_{x} H_{y} O_{z}\right)+159 \cdot 19 u(O) \stackrel{\text { burnt }}{\longrightarrow} 175 \cdot 38 u\left(\mathrm{CO}_{2}\right)+71 \cdot 81 u\left(\mathrm{H}_{2} \mathrm{O}\right)$

For removing the quantity of oxygen that has combined with butyric acid from the above equation, it can be written as,

$: 88 u\left(C_{x} H_{y} O_{z}\right) \stackrel{\text { burnt }}{\longrightarrow}\left\{175 \cdot 38 u\left(\mathrm{CO}_{2}\right)+71 \cdot 81 u\left(\mathrm{H}_{2} \mathrm{O}\right)\right\}-159 \cdot 19 u(O)$

Splitting of quantities with respect to the atomic weights of their elements are done as following

$: 88 u\left(C_{x} H_{y} O_{z}\right) \rightarrow[175.38 u\{12(C)+32(O)\}+71.81 u(2(H)+16(O)]-159.19 u(O)$

Proportionate quantities of each element of the compounds are written as following. Here conversion factors are $\frac{175.38}{12+32}$ and $\frac{71.81}{2+16}$, these two terms are equal to 3.99 and 3.99 .

$: \rightarrow[\{12 \times 3.99(C) u+32 \times 3.99(O) u\}+(2 \times 3.99(H) u+16 \times 3.99(O) u]-159.19 u(O)$

$: \rightarrow[\{47.88 u(C)+127.68 u(O)\}+(7.98 u(H)+63.84 u(O)]-159.19 u(O)$

To remove only oxygen that has combined with butyric acid, following method is adopted.

$: \rightarrow[47.88 u(C)+191.38 u(O)+7.98 u(H)]-159.19 u(O)$

$: \rightarrow 47.88 u(C)+7.98 u(H)+32.19 u(O)$

Rounding off the numbers to zero decimal places, we have

$: \rightarrow 48 u(C)+8 u(H)+32 u(O)$

Dividing each term by their atomic masses, respectively, the above equation will give the molecular formula. i.e., by dividing, $\mathrm{C}$ by $12 \mathrm{u}, \mathrm{H}$ by $1 \mathrm{u}$ and $\mathrm{O}$ by $16 \mathrm{u}$, we get,

$: \rightarrow 4(C)+8(H)+2(O)$

Consequently this can be written as, $\left(\mathrm{C}_{x} \mathrm{H}_{y} \mathrm{O}_{z}\right)=\left(\mathrm{C}_{4} \mathrm{H}_{8} \mathrm{O}_{2}\right)$

Percentage of each element of the compound are found as following

$\left(\mathrm{C}_{x} \mathrm{H}_{y} \mathrm{O}_{z}\right)=\left(\mathrm{C}_{4} \mathrm{H}_{8} \mathrm{O}_{2}\right)$

Multiplying atomicities of elements of the compound by their atomic masses, we get,

$88(C, H, O)=48(C), 8(H), 32(O)$

To make the sum of coefficients of RHS equal to 100 , above relation is multiplied by $\frac{100}{88}$ throughout. And rounding off to zero decimal places, we have,

$100(C, H, O)=55(C), 9(H), 36(O)$

Dividing the above equation by 100 , throughout, we get, [1]

$100 \%(C, H, O)=55 \%(C), 9 \%(H), 36 \%(O)$

This is the percentage composition of each element in butyric acid

\section{Law of Multiple Proportions}

4.01. Carbon and Oxygen are known to form two compounds. The carbon content in one of these $42.9 \%$ while in the other, it is $27.3 \%$. Show that the data are in agreement with the law of proportions.[6].

Solution:

$100 \%$ of first compound of carbon and Oxygen is $=42.9 \%(\mathrm{C})+(100-42.9) \%(\mathrm{O})$

$$
=42 \cdot 9 \%(C)+57 \cdot 1 \%(O)----(5)
$$

$100 \%$ of second compound of carbon and Oxygen is $=27.3 \%(\mathrm{C})+(100-27.3) \%(\mathrm{O})$

$$
=27 \cdot 3 \%(C)+72 \cdot 7 \%(O)----(6)
$$

Divide equation (5) and (6) by their respective percentages of carbon, throughout. we have,

Note: while dividing we may neglect the symbol of element or retain them.

Then equation (5) and (6) will be as following.

$:=1+1 \cdot 3$

$:=1+2 \cdot 6$

Now, the ratio of Oxygen is $1 \cdot 3: 2 \cdot 6=1: 2$

This shows that data is in agreement with the law of multiple proportions.

4.02. Three oxides of lead on analysis were found to contain lead as under:

i. $\quad 3.45 \mathrm{~g}$ of yellow oxide contains $3.21 \mathrm{~g}$ of lead

ii. $\quad 1.195 \mathrm{~g}$ of brown oxide contains $1.035 \mathrm{~g}$ of lead 
$1.77 \mathrm{~g}$ of red oxide contains $1.61 \mathrm{~g}$ of lead.

Show that these data illustrate law of multiple proportions.[7]

Solution:

: Mass of yellow oxide $3.45 g=3 \cdot 21 g(P b)+(3 \cdot 45 g-3 \cdot 21 g)(O)$

: $\quad=3 \cdot 21 g(P b)+0 \cdot 24 g(0)------(7)$

: Mass of brown oxide $1 \cdot 195 g=1 \cdot 035 g(P b)+(1 \cdot 195 g-1.035 \cdot g)(O)$

$: \quad=1 \cdot 035 \mathrm{~g}(\mathrm{~Pb})+0 \cdot 16(0)-------(8)$

: $\quad$ Mass of red oxide $1 \cdot 77 \mathrm{~g}=1 \cdot 61 \mathrm{~g}(\mathrm{~Pb})+(1 \cdot 77 \mathrm{~g}-1 \cdot 61 \mathrm{~g})(\mathrm{O})$

$: \quad=1 \cdot 61 \mathrm{~g}(\mathrm{~Pb})+0 \cdot 16(0)-------(9)$

Divide equations (7),(8),(9) by their weights of lead and neglecting the symbols of elements, we have.

$:=1+0 \cdot 075$

$:=1+0 \cdot 15$

$:=1+0 \cdot 1$

:Then, 0.075: 0.15: $0.1=3: 6: 4$

Note: to convert decimal numbers to natural numbers, find the place value of the right most significant digit of all the numbers in the given set of ratio. Inverse them. Multiply all the elements of the ratio by the largest number. And divide it by GCD of the numbers so obtained. We get the result.

4.03. Nitrogen and Oxygen combines to form five oxides namely Nitrous Oxide $\mathrm{N}_{2} \mathrm{O}$, Nitric Oxide $\mathrm{NO}$, Nitrogen trioxide $\mathrm{N}_{2} \mathrm{O}_{3}$, Nitrogen tetroxide $\mathrm{N}_{2} \mathrm{O}_{4}$, Nitrogen pentoxide $\mathrm{N}_{2} \mathrm{P}_{5}$. The different weights of oxygen that combine with the fixed weight of oxides in all these are calculated as following. [8]

To start with, $\left(\mathrm{N}_{2}, \mathrm{O}\right)$ with its atomic mass. $\rightarrow\{2 \times 14(\mathrm{~N}), 16(\mathrm{O})\}$

Divide the above relation by 2 which is the factor of 14 to get result for $14(\mathrm{~N})$

$:$ i.e., $\rightarrow \frac{\{2 \times 14(N), 16(O)\}}{2}$

$: \rightarrow 14(N), 8(O)$

: Similarly, for $(N, O) \rightarrow 14(N), 16(O)$

$: N_{2}, O_{3}, \rightarrow 14(N), 24(O)$

$:\left(N_{2}, O_{4}\right) \rightarrow 14(N), 32(O)$

$:\left(N_{2}, O_{5}\right) . \rightarrow 14(N), 40(O)$

8: $16: 24: 32: 40$

1: $2: 3: 4: 5$

\section{Law of reciprocal proportions}

5.01. Hydrogen sulphide $\left(\mathrm{H}_{2} \mathrm{~S}\right)$ contains $94.11 \%$ sulphur, Water $\left(\mathrm{H}_{2} \mathrm{O}\right)$ contains $11.11 \%$ hydrogen and sulphur dioxide contains $\left(\mathrm{SO}_{2}\right) 50 \%$ oxygen. Show that the results are in agreement with law of reciprocal proportions.[9]

Solution:

Percentage composition of $\left(\mathrm{H}_{2} \mathrm{O}\right)=(11.11) \%(\mathrm{H})+(100-11.11) \%(\mathrm{O})$

$$
=11 \cdot 11 \%(H)+88 \cdot 89 \%(O)-------(10)
$$

: Similarly, Percentage composition of $\left(\mathrm{SO}_{2}\right)=50 \%(\mathrm{~S})+50 \%(\mathrm{O})------------(11)$

$: \quad$ And of $\left(H_{2} S\right)=5 \cdot 89 \%(H)+94 \cdot 11 \%(S)----------(12)$

To make $88.89 \%$ of oxygen in (10), equal to $50 \%$ for comparison with (11). We need to multiply (10) by $\frac{50}{88.89}$

: i.e., Percentage composition of $\left(\mathrm{H}_{2} \mathrm{O}\right)=\left[11 \cdot 11 \times\left(\frac{50}{88 \cdot 89}\right)\right] \%(\mathrm{H})+\left[88 \cdot 89 \times\left(\frac{50}{88 \cdot 89}\right)\right] \%(\mathrm{O})$

$$
=6 \cdot 22 \%(H)+50 \%(O)------(13)
$$

: $\quad$ Similarly, $\left(\mathrm{SO}_{2}\right)=50 \%(\mathrm{~S})+50 \%(\mathrm{O})---------(14)$

Now the ratio of two different elements, hydrogen and sulphur w.r.t same quantity of third element, oxygen is $6.22(H): 50(S)=1(H): 8(S)----(15)$

Whereas, ratio of combination of hydrogen and sulphur in $\left(\mathrm{H}_{2} \mathrm{~S}\right)$ is

: 5.89\% $(H): 94.11 \%(S)=1(H): 16(S)------(16)$

Then, the ratio of (15) and (16) are $\frac{1}{8}: \frac{1}{16}$

This is equal to $2: 1$

Thus, law of reciprocal proportion is illustrated. 


\subsection{Calculate}

\section{Density of water}

(a) The actual volume of one molecule of water

(b)The radius of a water molecule assuming to be spherical (density of water $\left.=1 \mathrm{~g} \mathrm{~m}^{-1}\right)$.[10]

Comments: the result of this problem given in the book leads to wrong impression that the water molecules occupy all the space available in $1 \mathrm{~cm}^{3}$ or $1 \mathrm{ml}$ of volume, completely.

On [11] it is said that the distance between oxygen and hydrogen in the water molecule is $1.00 \AA$. This value with the value of atomic radius of hydrogen can be considered as the radius of the sphere of water molecule.

But, the result obtained in this problem of the book is longer than $1.00 \AA+0.53 \AA=1.53 \AA$. Hence the solution of the problem leads to ambiguity.

\subsection{True Density}

Till now it has not been possible to find the absolute density or true density. The densities that we know at present are variable with respect to different parameters.

Here an attempt is made to approach towards absolute or true density.

A progress towards true density is as following.

True density of water may also be called as theoretical density of water because such state of water is not seen till now. And it is an imagined and ideal case.

\subsection{Density Of Water Derived With Reference To Sum Of Bond Length And Atomic Radius Of Hydrogen (Theoretical Density).}

The value of density of water that we are using at present is the apparent density which is chosen as a reference value on specified conditions.

i.e., the density of water at $4^{\circ} \mathrm{C}$ is 1 mass unit / 1 vol.unit

Density Of Water With Reference To sum of Bond Length of water and radius of hydrogen atom is : sum of mass of molecules of water

$=\overline{\text { sum of volumes of cubes that circumscribes the molecules of water }}$

This value will be the maximum value of density of water, if by any means the inter-molecular space is removed out, excluding the space between tangential points (points of contacts) of the molecule. In this case shape of the molecule is considered as spherical.

This value of density is also not good approximation because shape of water molecules is thought off as tetrahedral. Although, this is just an endeavor to approach the true value of density of water.

Weight of $1 \mathrm{~cm}^{3}$ of water at $3 \cdot 97^{\circ} \mathrm{C}$ or approximately $4^{\circ} \mathrm{C}$ is $1 \mathrm{~g}$

1 mole of water $=18 \mathrm{~g}$ of water $=18 \mathrm{~cm}^{3}$ of water $=18 \mathrm{ml}$ of water

$18 \mathrm{~cm}^{3}$ of water contains $6 \cdot 022 \times 10^{23}$ molecules

$1 \mathrm{~cm}^{3}$ of water contains $\frac{6 \cdot 022 \times 10^{23}}{18}$ molecules

$$
=3.34 \times 10^{22} \text { molecules }
$$

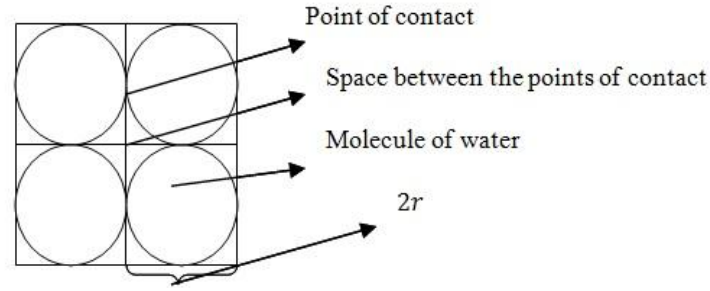

Figure-1: Imaginary arrangement of water molecules in water. Considering, shape of the water spherical. And it is showing the space between the points of contacts.

Sum of Bond length between Oxygen and hydrogen and the atomic radius of Hydrogen in the water molecule can be taken as the approximate value of radius of the imaginary sphere of the water molecule. Values of bond length of water molecule and radius of hydrogen atom are $95.87 \mathrm{pm}$ and $53 \mathrm{pm}$ respectively. Hence, radius of the sphere of the molecule of water which can be denoted by,

$: r=9 \cdot 59 \times 10^{-9} \mathrm{~cm}+5.3 \times 10^{-9} \mathrm{~cm}$

$:=(9.59+5.3) 10^{-9} \mathrm{~cm}$

$:=1.489 \times 10^{-8} \mathrm{~cm}$

$:=1.489 \AA$

It is presumed that the volume of $1 \mathrm{~cm}^{3}$ of water is brought down by removing the space between the molecules, except the space between the points of contacts of the spheres of water molecules which is not possible to remove because, shape of the molecules are spherical. 
The molecules of water can be imagined as kept in a cube of length equal to $2 \mathrm{r}$

Then the volume of each such cube is $=(2 r)^{3}$

$:=\left\{2 \times\left(1.489 \times 10^{-8}\right)\right\}^{3} \mathrm{~cm}^{3}$

$:=\left(2.641 \times 10^{-23}\right) \mathrm{cm}^{3}$

Total volume of $3.34 \times 10^{22}$ molecules including the volume between the points of contacts of spheres is $:=\left(3.34 \times 10^{22}\right) \times\left(2.641 \times 10^{-23}\right) \mathrm{cm}^{3}$

$:=\left(2 \cdot 34 \times 10^{-1}\right) \mathrm{cm}^{3}$

$:=0.882 \mathrm{~cm}^{3}$

Density of water at this stage is $=\frac{1 \mathrm{~g}}{0 \cdot 882 \mathrm{~cm}^{3}}$

$:=1.134 \mathrm{~g} / \mathrm{cm}^{3}$

This is the maximum value of density of water that it can take at this condition.

This can be considered as standard density to compare with other densities.

Now the percentage of minimum space that water molecules can occupy when compressed such that no occupiable space is available except the space between the points of contacts.

$1 \mathrm{~cm}^{3}$ of volume of water $=0.882 \mathrm{~cm}^{3}$ of water molecules $+(1-0.882) \mathrm{cm}^{3}$ of unoccupied space

: $\quad=0.882 \mathrm{~cm}^{3}$ of water molecules $+0.118 \mathrm{~cm}^{3}$ of un occupied space

Multiplying the above by the factor $\frac{100}{100}$, and neglecting the units, we have

$: \frac{100}{100}=0.882 \times\left(\frac{100}{100}\right)+0.118 \times\left(\frac{100}{100}\right)$

$: 100 \%=88.2 \%+11.8 \%$

This shows that out of $1 \mathrm{ml}, 88.2 \%$ of space is occupied by the water molecules (including the space remains unoccupied between the molecules) and $11.8 \%$ empty space will remain unoccupied.

Therefore we can say that $88.2 \% v / v$ of water molecules have spread over $1 \mathrm{~cm}^{3}$ space in a definite pattern.

Conclusion: $3.34 \times 10^{22}$ molecules of water are spread across $1 \mathrm{~cm}^{3}$ of volume in a definite pattern by the influence of inter molecular electrostatic forces.

Also, we can say that gases entering liquid state means, molecules or atoms of gases are taking a definite pattern.

Further, Liquids entering solid state means, they are getting definite pattern and shape, sometimes particular shape.

\section{Percentage composition}

7.01. $1.0 \mathrm{~g}$ of a mixture of carbonate of calcium and magnesium gave $240 \mathrm{ml}$ of $\mathrm{CO}_{2}$ at N.T.P. calculate percentage of the composition of the mixture.[12]

Solution:

Let $x$ and $y$ be the quantities of $\mathrm{CaCO}_{3}$ and $\mathrm{MgCO}_{3}$ respectively.

$100 x \mathrm{~g}$ of $\mathrm{CaCO}_{3}$ releases $22400 \times \mathrm{ml}$ of $\mathrm{CO}_{2}$

And, $x \mathrm{~g}$ of $\mathrm{CaCO}_{3}$ releases $\frac{22400 x}{100} \mathrm{ml}$ of $\mathrm{CO}_{2}$

$:=224 \times \mathrm{ml}$

$84 y \mathrm{~g}$ of $\mathrm{MgCO}_{3}$ releases 22400 y $\mathrm{ml}$ of $\mathrm{CO}_{2}$

And,y $\mathrm{g}$ of $\mathrm{CaCO}_{3}$ releases $\frac{22400 \mathrm{y}}{84} \mathrm{ml}$ of $\mathrm{CO}_{2}$

$:=266.7$ y $\mathrm{ml}$

Forming simultaneous equations using the available data, we have

: $224 x+266.7 y=240----(17)$

: $\quad x+y=1-----(18)$

To find the unknowns, determinant method can be used

: Determinent,$\Delta=\left|\begin{array}{cc}224 & 266.7 \\ 1 & 1\end{array}\right|$

$:=-42.7$

: component determinant of $x$ is $\Delta_{x}=\left|\begin{array}{cc}240 & 266.7 \\ 1 & 1\end{array}\right|$

$:=-26.7$

$: x=\frac{\Delta_{x}}{\Delta}$

$:=\frac{-26.7}{-42.7}$

$:=0.625$

Putting this value of $x$ in equation (18) we get 
$: y=0.375$

Dividing and multiplying the values of $x$ and $y$ by $\frac{100}{100}$, we get

$: x \%=62.5 \%$ and $y \%=37.5 \%$

\section{Establishing relation between Molarity, Molality and Mole fraction.}

Equations related to Molarity, Molality and Mole fraction, are although inter related, presently they are appearing as different form of equations. This may cause exam fear in students. To ward off this fear, inter relations between the equations are established.

\subsection{Molarity of solution}

Verbal equation of, Molarity $=\frac{\text { No. of moles of solute }}{\text { volume of solution in one liter }}$

Please note that volume of solution is not expressed in liters instead it is expressed as only one liter. i.e., the solute is understood, only with reference to one liter of solution. Therefore in the denominator of above relation the phrase one liter is used instead of liters.

Further, if the number of moles of solute is denoted by $x \mathrm{~mol}$, and volume of solution in liter by $\mathrm{L}$, we get the equation as following

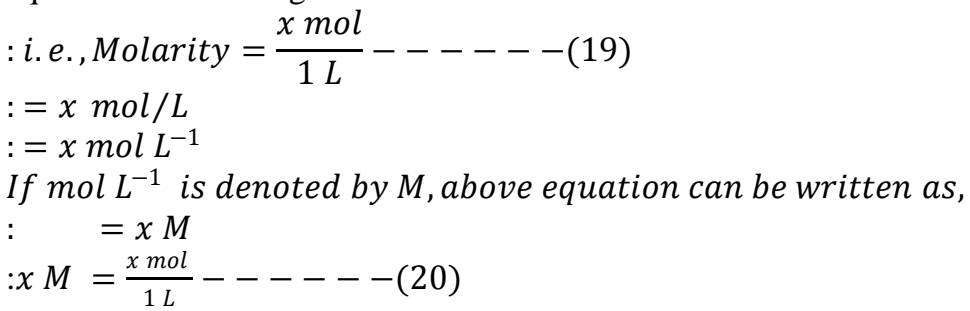

Consequently, molarity is related to weight by volume equation, i.e., $x M(w / v)$

\subsection{Molality}

Moreover, we know that Density, $D=\frac{W}{V}, W$ is the weight and $V$ is the volume of the solution,

Also, Density can be written as $D=\frac{w g}{m l}$

where $w g$ is $w$ grams, hence ratio indicates $w$ grams per $m l$

: Hence, $1 \mathrm{ml}=\frac{w g}{D}-------(21)$

Substituting RHS of (21) in (20), we have,

$: x M=\frac{x \mathrm{~mol}}{1000 \times \frac{w g}{D}}$

$:=\frac{D x \mathrm{~mol}}{1000 \mathrm{wg}}$

$: \frac{x M}{D}=\frac{x \mathrm{~mol}}{1000 \mathrm{wg}}$

With reference to [1] it can be written as

$:=\frac{x \mathrm{~mol}}{(1000 \mathrm{wg}-x \mathrm{~mol})+x \mathrm{~mol}}$

With reference to [1] it can also be written as

$:=\frac{x \mathrm{~mol}}{(1000 \mathrm{wg}-x \mathrm{~mol})}+\frac{0}{x \mathrm{~mol}}------$

In the first expression of the RHS of the above equation, the denominator $1000 \mathrm{wg}-x \mathrm{~mol}$ is not subtractable because it contains different units. Hence $x \mathrm{~mol}$ is multiplied by its molar mass to convert it into grams.

: i.e., $x$ mol $=x\left(\frac{\text { mass of solute in gram equal to molar mass }}{\text { Molar mass }}\right)$

$: x$ mol $\times$ Molar mass $=x \times$ mass of solute in grams equal to molar mass

Let this be $=n g$

Putting this value only in the first expression of RHS of (23) we have,

$: \frac{x M}{D}=\frac{x \mathrm{~mol}}{(1000 w g-n g)}+\frac{0}{x \mathrm{~mol}}----$

Now it is required to analyze the LHS of (24) 


$$
\begin{aligned}
& :=\frac{x M}{D} \\
& :=\frac{x \mathrm{~mol}}{L D} \\
& :=\frac{x \mathrm{~mol}}{1000 \mathrm{ml} \times\left(\frac{w g}{m l}\right)} \\
& :=\frac{x \mathrm{~mol}}{1000 \mathrm{wg}} \times \frac{x \mathrm{~mol}}{x \mathrm{~mol}} \\
& :=\frac{(1000 \mathrm{wg}-x \mathrm{~mol})+x \mathrm{~mol}}{:=} \\
& :(1000 \mathrm{wg}-\mathrm{ng})
\end{aligned}
$$

Consequently, (24) can be written as

$$
: \frac{x \mathrm{~mol}}{(1000 w g-n g)}+\frac{0}{x \mathrm{~mol}}=\frac{x \mathrm{~mol}}{(1000 w g-n g)}+\frac{0}{x \mathrm{~mol}}
$$

After elimination of $\frac{0}{x \mathrm{~mol}}$ we have,

$$
: \frac{x \mathrm{~mol}}{(1000 w g-n g)}=\frac{x \mathrm{~mol}}{(1000 w g-n g)}
$$

It can also be written as,$\frac{x \mathrm{~mol}}{(1000 w-n) g}=\frac{x \mathrm{~mol}}{(1000 w-n) g}$

Now it is required to make the denominator equal to $1000 \mathrm{~g}$, hence it is multiplied by the factor $\frac{1000}{1000 w-n}$

$$
\begin{aligned}
& :=\frac{x \mathrm{~mol} \times\left(\frac{1000}{1000 w-n}\right)}{(1000 w-n) g \times\left(\frac{1000}{1000 w-n}\right)} \\
& : \frac{\left(\frac{1000 x \mathrm{~mol}}{1000 w-n}\right)}{1000 \mathrm{~g}}=\frac{\left(\frac{1000 \times \mathrm{mol}}{1000 w-n}\right)}{1000 \mathrm{~g}}-- \\
& \text { Let }, \frac{1000 x}{1000 w-n}=a
\end{aligned}
$$

Then, LHS of (25) will be,

$$
\begin{aligned}
\text { : } \quad \frac{a \mathrm{~mol}}{1000 \mathrm{~g}}=\frac{\left(\frac{1000 \times \mathrm{mol}}{1000 \mathrm{~W}-\mathrm{n}}\right)}{1000 \mathrm{~g}}----(26) \\
\text { a mol } \mathrm{Kg}^{-1}=\frac{\left(\frac{1000 \times \mathrm{mol}}{1000 \mathrm{~W}-\mathrm{n}}\right)}{1000 \mathrm{~g}}
\end{aligned}
$$

If $\mathrm{mol} \mathrm{Kg}^{-1}$ is denoted by m, we have,

$$
\text { : } \quad a m=\frac{\left(\frac{1000 \times \mathrm{mol}}{1000 \mathrm{w}-\mathrm{n}}\right)}{1000 \mathrm{~g}}-------(27)
$$

\subsection{Mole Fraction}

Mole fraction takes only one unit that is moles. Whereas in molarity and molality two units are used that are mol and gram. Hence molarity and molality are irregular comparisons.

Now, LHS of (27) is considered to continue the journey towards Mole fraction.

$$
\text { : i.e., } \frac{a \mathrm{~mol}}{1000 \mathrm{~g}}
$$

Here, numerator is indicating quantity of solute in moles and the denominator is indicating the quantity of solvent in grams. Hence the comparison is uneven. To make it even, denominator is converted to moles by dividing it by molar mass of solvent.

$$
\begin{aligned}
& :=\frac{a \mathrm{~mol}}{\left(\frac{1000 \mathrm{~g}}{\text { Molar mass }}\right)}---- \\
& : \text { Let }, \frac{1000 \mathrm{~g}}{\text { Molar mass }}=b \mathrm{~mol} \\
& : \text { Then (28)will be },=\frac{a \mathrm{~mol}}{b \mathrm{~mol}}
\end{aligned}
$$


Here numerator is the quantity of solute and denominator is solvent. Now to make the denominator a solution, 'a mol'of solute is added.

: i.e., $=\frac{a \mathrm{~mol}}{b \mathrm{~mol}}+\frac{0}{a \mathrm{~mol}}$

$:=\frac{a \mathrm{~mol}}{a \mathrm{~mol}+\mathrm{bmol}}$

:If the result of the above equation is $x_{a}$ then, $x_{a}=\frac{a m o l}{a m o l+b m o l}----(29)$

(29) Indicates the equation for Mole fraction of solute .

Further to draw equation for Mole fraction of solvent consider the inverse of LHS of (26).

: i.e., $\frac{1000 \mathrm{~g}}{\mathrm{amol}}$

: When transformed into same units, the above expression will be $=\frac{b \mathrm{~mol}}{a \mathrm{~mol}}$

: When same quantity of solvent is added,$=\frac{b \mathrm{~mol}}{a \mathrm{~mol}}+\frac{0}{b \mathrm{~mol}}$

$:=\frac{b \mathrm{~mol}}{a \mathrm{~mol}+b \mathrm{~mol}}$

:If the result of the above equation is $x_{b}$ then, $x_{b}=\frac{b \mathrm{~mol}}{a \mathrm{~mol}+b \mathrm{~mol}}----(30)$

Similarly, (30)indicates the equation of mole fraction of solvent.

Thus, link between Molarity, Molality and Mole fractions are established.

Moreover, general equation for mole fraction for more than one solute in a solution of one solvent is given as following. i.e., mono-solvent with multi-solute solution.

If $a_{1}, a_{2}, a_{3} \cdots a_{j}$ are different solutes in a solution then (29) and (30)will be

$: \frac{a_{1} m o l}{\left(a_{1} m o l+a_{2} m o l+a_{3} m o l \cdots+a_{j} m o l\right)+b m o l}-------$

$: \frac{b \mathrm{~mol}}{\left(a_{1 \mathrm{~mol}}+a_{2 \mathrm{~mol}}+a_{3 \mathrm{~mol}} \cdots+a_{\text {mol }}\right)+b \mathrm{~mol}}$

For brevity, let, $\left(a_{1} \mathrm{~mol}+a_{2} \mathrm{~mol}+a_{3} \mathrm{~mol} \cdots+a_{j} \mathrm{~mol}\right)=c \mathrm{~mol}$

Consequently,

$: \frac{a_{1} \mathrm{~mol}}{c \mathrm{~mol}+b \mathrm{~mol}}+\frac{a_{2} \mathrm{~mol}}{c \mathrm{~mol}+b \mathrm{~mol}}+\frac{a_{3} \mathrm{~mol}}{c \mathrm{~mol}+b \mathrm{~mol}}+\cdots+\frac{a_{\mathrm{i}} \mathrm{mol}}{c \mathrm{~mol}+b \mathrm{~mol}}+\frac{b \mathrm{~mol}}{c \mathrm{~mol}+b \mathrm{~mol}}=1$

8.04. Further to find the ratio of solute and solvent (29) is continued as following

$: x_{a}=\frac{a m o l}{a m o l+b m o l}$

$: a \mathrm{~mol}=x_{a}(\mathrm{amol})+x_{a}(\mathrm{bmol})$

$: a \mathrm{~mol}-x_{a}(a \mathrm{~mol})=x_{a}(\mathrm{~b} \mathrm{~mol})$

$: a \operatorname{mol}\left(1-x_{a}\right)=x_{a}(b \mathrm{~mol})$

$: \frac{a m o l}{b m o l}=\frac{x_{a}}{\left(1-x_{a}\right)}-----(34)$

Here, the values are related to mole unit. To convert them to conventional unit which is usually gram, they are multiplied by molar masses in grams.

$: \frac{a \mathrm{~mol}}{b \mathrm{~mol}}=\frac{x_{a} \times \text { molar mass of solute }}{\left(1-x_{a}\right) \times \text { molar mass of solvent }}$

If the value of numerator and denominator are denoted by $\mathrm{a}$ and $\mathrm{b}$ respectively, above equation can be written as,

$: \frac{a m o l}{b m o l}=\frac{c g}{d g}-$

8.04. General equation for the conversion of percentage strength to Molarity.

$: x \% w / v$, solution $=\left(\frac{10 x}{\text { molar mass }}\right) M------(37)$

:Proof: Given, $x \% w / v=\frac{x g}{100 \mathrm{~cm}^{3}}$, 
$:=\frac{\left(\frac{x g}{m o l}\right) \mathrm{mol}}{\frac{1000 \mathrm{~cm}^{3}}{10}}$

$:=\left(\frac{10 x}{m o l}\right)\left(\frac{m o l}{1 L}\right)$

$:=\left(\frac{10 x}{\text { molar mass }}\right) M$

$:=R H S$

Thus proved.

8.05. Similarly, equation for any strength of solution which is denoted by $x P P n i s,[1]$

: Molarity of XPPn solution $(w / v)=\left(\frac{1000 x}{n \times \text { molar mass }}\right) M-----(38)$

8.06. Derivation of mathematical expression for Molarity of $x P P n$ solution:

$: x P \operatorname{PPn}(w / v$ solution $)=\frac{x}{n \mathrm{~cm}^{3}}$

$:=\frac{\left(\frac{x}{1 \mathrm{~mol}}\right) 1 \mathrm{~mol}}{n \mathrm{~cm}^{3}}$

$:=\frac{\left[\left(\frac{x}{1 \mathrm{~mol}}\right) 1 \mathrm{~mol}\right]\left(\frac{1000}{n}\right)}{n \mathrm{~cm}^{3} \times\left(\frac{1000}{n}\right)}$

$:=\frac{\left(\frac{1000 x}{n \times 1 \mathrm{~mol}}\right) 1 \mathrm{~mol}}{1000 \mathrm{~cm}^{3}}$

$:=\left(\frac{1000 x}{n \times 1 \mathrm{~mol}^{2}}\right) \mathrm{mol} \mathrm{L}^{-1}$

$:=\left(\frac{1000 x}{n \times 1 \mathrm{~mol}}\right) M$

$:=\left(\frac{1000 x}{n \times \text { molar mass }}\right) M$

Thus, equation is derived.

8.07. $2.46 \mathrm{~g}$ of sodium hydroxide (molar mass $=40$ ) are dissolved in water and solution is made to $100 \mathrm{~cm}^{3}$ in a volumetric flask. Calculate the molarity of the solution.[13]

Solution:

Method 1:

Data: Amount of $\mathrm{NaOH}=2.46 \mathrm{~g}$

Molar mass of $\mathrm{NaOH}=40$

Volume of solution $=100 \mathrm{~cm}^{3}$

Prepared, NaoH solution can be written mathematically as,

$:=\frac{2.46 \mathrm{~g}}{100 \mathrm{~cm}^{3}}$

Which means $100 \mathrm{~cm}^{3}$ of solution contains $2.46 \mathrm{~g}$ of solute. Therefore molarity is hidden in the above ratio

Since $2.46 \mathrm{~g}=\frac{2.46}{40}$ moles

$:=0.0165$ mole

Substituting this value in (40)we have, $x M=\frac{0.0165 \mathrm{~mol}}{100 \mathrm{~cm}^{3}}$

To make the above relation look like(20)it is written as, $x M=\frac{0.0165 \mathrm{~mol}}{\left(\frac{1000 \mathrm{~cm}^{3}}{10}\right)}$

$: x M=\frac{0.0165 \times 10 \mathrm{~mol}}{1000 \mathrm{~cm}^{3}}$

$: x M=\frac{0.165 \mathrm{~mol}}{1000 \mathrm{~cm}^{3}}$

$:=0.615 \mathrm{~mol} \mathrm{~L}^{-1}$

$:=0.615 \mathrm{M}$

Method 2:

Using relation (37) we have, 
$x M=\left(\frac{24.6}{40}\right) M$

$=0.615 M$

Method 3: Using (38)

$x M=\frac{1000 \times 2.46}{100 \times 40}$

$=0.615 \mathrm{M}$

8.08. Calculate the molality of a solution containing $20.7 \mathrm{~g}$ of potassium carbonate dissolved in $500 \mathrm{ml}$ of solution $\quad$ (assume density of solution $\left.=1 \mathrm{~g} \mathrm{~mL}^{-1}\right)$.[14]

Solution:

Data: Mass of $\mathrm{K}_{2} \mathrm{CO}_{3}=20 \cdot 7 / 500 \mathrm{ml}$

$$
=41.4 / 1000 \mathrm{ml}
$$

Molar mass of $\mathrm{K}_{2} \mathrm{CO}_{3}=138$

We can solve by using (27)

$$
\begin{aligned}
\text { i.e., } a m & =\frac{\left(\frac{1000 \times \mathrm{mol}}{1000 \mathrm{~W}-\mathrm{n}}\right)}{1000 \mathrm{~g}} \\
& =\frac{\left(\frac{1000\left(\frac{\mathrm{mass} / 1000 \mathrm{ml}}{\text { molar mass }}\right) \mathrm{mol}}{1000 \mathrm{~W}-\mathrm{n}}\right)}{1000 \mathrm{~g}} \\
: \quad & =\frac{\frac{1000 \times\left(\frac{41.4}{138}\right) \mathrm{mol}}{1000-41.4}}{1000 \mathrm{~g}} \\
: \quad & =\frac{\left(\frac{300 \mathrm{~mol}}{958.6}\right)}{1000 \mathrm{~g}} \\
: \quad & =0.313 \mathrm{~m}
\end{aligned}
$$

8.09. What volume of $10 \mathrm{M} \mathrm{HCl}$ and $3 \mathrm{M} \mathrm{HCl}$ should be mixed to get $1 \mathrm{~L}$ of $6 \mathrm{M} \mathrm{HCl}$ solution?[15]

Solution:

$10 \mathrm{M} \mathrm{HCl}=\frac{10 \mathrm{~mol} \text { of } \mathrm{HCl}}{1 \mathrm{~L}}$ and $3 \mathrm{M} \mathrm{HCl}=\frac{3 \mathrm{~mol} \text { of } \mathrm{HCl}}{1 \mathrm{~L}}$

Let, $x$ and $y$ be the factors that transforms the $10 \mathrm{M} \mathrm{HCl}$ and $3 \mathrm{M} \mathrm{HCl}$ to

the required concentation.

Then, mixing of these two solutions of unknown concentrations can be written mathematically as following.

$: \frac{10 x \mathrm{~mol} \text { of } \mathrm{HCl}}{x \mathrm{~L}}+\frac{3 y \mathrm{~mol} \text { of } \mathrm{HCl}}{y \mathrm{~L}}=\frac{6 \mathrm{~mol}}{1 \mathrm{~L}}$

Consequently,

$: 10 x+3 y=6$

$: x+y=1$

Solving the above equation for $\mathrm{x}$, and, $\mathrm{y}$ we get,

$: x=\frac{3}{7}$ and $y=\frac{4}{7}$

Ratio of mixing is $3: 4$

For $1 \mathrm{~L}, 429 \mathrm{ml}$ of $10 \mathrm{M} \mathrm{HCl}$ and $571 \mathrm{ml}$ of $3 \mathrm{M} \mathrm{HCl}$ to be mixed.

8.10. What volume of $0.6 \mathrm{M} \mathrm{HCl}$ has enough hydrochloric acid to react exactly with $25 \mathrm{ml}$ of aqueous $\mathrm{NaOH}$ having concentration of $0.5 \mathrm{M}$ ?[16]

Solution:

Method 1: Given, unknown volume of $0.6 \mathrm{M} \mathrm{HCl}$ solution and $25 \mathrm{ml}$ of $0.5 \mathrm{M} \mathrm{NaOH}$ solution. Now the LHS of equation of the reaction can be written as,

$: 0.6 \mathrm{M} \mathrm{HCl}(a q)+0.5 \mathrm{M} \mathrm{NaOH}(a q) \rightarrow$

It can also be written as $\frac{0.6 \mathrm{~mol} \mathrm{HCl}}{1000 \mathrm{ml}}+\frac{0.5 \mathrm{~mol} \text { of } \mathrm{NaOH}}{1000 \mathrm{ml}} \rightarrow$ 
From the equation it is clear that equal moles of reactants $\mathrm{A}$ and $\mathrm{B}$ react completely with one another, without leaving residue of reactant. In the above expression, $\mathrm{HCl}(a q)$ exceeding the equality by $0.1 \mathrm{M}$. And by simple observation we can find that the factor required for equalizing the expression is $\frac{0.5}{0.6}$. Multiplying both the denominator and numerator by this factor, we have,

$$
\begin{aligned}
& : \frac{0.6 \times\left(\frac{0.5}{0.6}\right) \mathrm{mol} \mathrm{HCl}}{1000 \times\left(\frac{0.5}{0.6}\right) \mathrm{ml}}+\frac{0.5 \mathrm{~mol} \mathrm{of} \mathrm{NaOH}}{1000 \mathrm{ml}} \rightarrow \\
& : \frac{0.5 \mathrm{~mol} \mathrm{HCl}}{833.33 \mathrm{ml}}+\frac{0.5 \mathrm{~mol} \mathrm{of} \mathrm{NaOH}}{1000 \mathrm{ml}} \rightarrow
\end{aligned}
$$

To get the result it is enough that 833.33 is multiplied by $\frac{25}{1000}$. although, to get the clear view of the equation LHS of the equation is multiplied by the factor $\frac{25}{1000}$. We choose this factor because given volume of $\mathrm{NaOH}$ is $25 \mathrm{ml}$.

$$
\begin{aligned}
& \text { : i.e. } \frac{0.5 \times\left(\frac{25}{1000}\right) \mathrm{mol} \mathrm{HCl}}{833.33 \times\left(\frac{25}{1000}\right) \mathrm{ml}}+\frac{0.5 \times\left(\frac{25}{1000}\right) \mathrm{mol} \mathrm{of} \mathrm{NaOH}}{1000 \times\left(\frac{25}{1000}\right) \mathrm{ml}} \rightarrow \\
& : \frac{0.125 \mathrm{~mol} \mathrm{HCl}}{20.83 \mathrm{ml}}+\frac{0.125 \mathrm{~mol} \mathrm{of} \mathrm{NaOH}}{25 \mathrm{ml}} \rightarrow
\end{aligned}
$$

$20.83 \mathrm{ml}$ of $0.6 \mathrm{M}$ solution of $\mathrm{HCl}$ is required to react exactly with $25 \mathrm{ml}$ of $0.5 \mathrm{M} \mathrm{NaOH}$ solution.

Method 2:

$: 0.6 \mathrm{M} \mathrm{HCl}(a q)+0.5 \mathrm{M} \mathrm{NaOH}(a q) \rightarrow$

It can also be written as $\frac{0.6 \mathrm{~mol} \mathrm{HCl}}{1000 \mathrm{ml}}+\frac{0.5 \mathrm{~mol} \text { of } \mathrm{NaOH}}{1000 \mathrm{ml}} \rightarrow-----(41)$

In the above expression $\mathrm{HCl}(a q)$ exceeding the equality by $0.1 \mathrm{M}$. Therefore to reduce $0.1 \mathrm{~mol}$ we need to decrease the volume of the solution.

Quantity of solution to be removed to decrease the 0.1 mol of solute is $\frac{\frac{0.6 \mathrm{~mol} \mathrm{HCl}}{6}}{\frac{1000 \mathrm{ml}}{6}}$

$:=\frac{0.1 \mathrm{~mol} \mathrm{of} \mathrm{HCl}}{166.67 \mathrm{ml}}$

To reduce this quantity from (1), we can write it as following,[1]

$:\left(\frac{0.6 \mathrm{~mol} \mathrm{HCl}}{1000 \mathrm{ml}}-\frac{0.1 \mathrm{~mol} \mathrm{of} \mathrm{HCl}}{166.67 \mathrm{ml}}\right)+\frac{0.5 \mathrm{~mol} \mathrm{of} \mathrm{NaOH}}{1000 \mathrm{ml}} \rightarrow$

By direct subtraction, we get, [1]

$:\left(\frac{0.5 \mathrm{~mol} \mathrm{HCl}}{833.33 \mathrm{ml}}\right)+\frac{0.5 \mathrm{~mol} \mathrm{of} \mathrm{NaOH}}{1000 \mathrm{ml}} \rightarrow$

To bring down to $25 \mathrm{ml}$ of $\mathrm{NaOH}$ divide and multiply each element of LHS by $\frac{25}{1000}$, we get

$: \frac{0.125 \mathrm{~mol} \mathrm{HCl}}{20.83 \mathrm{ml}}+\frac{0.125 \mathrm{~mol} \mathrm{of} \mathrm{NaOH}}{25 \mathrm{ml}} \rightarrow$

$20.83 \mathrm{ml}$ of $0.6 \mathrm{M}$ solution of $\mathrm{HCl}$ is required to react exactly with $25 \mathrm{ml}$ of $0.5 \mathrm{M} \mathrm{NaOH}$ solution.

8.11. Calculate the molarity and molality of a solution of ethanol in water if the mole fraction of ethanol is 0.05 and the density of solution is $0.997 \mathrm{~g} / \mathrm{cc}$. [20]

Solution: Given, $\frac{a \text { mol (solute) }}{\text { a mol (solute ) }+b \text { mol (solvent) }}=0.05$

considering (35) we have,

: i.e. $\frac{a \mathrm{~mol}}{b \mathrm{~mol}}=\frac{x_{a} \times \text { molar mass of solute }}{\left(1-x_{a}\right) \times \text { molar mass of solvent }}$

$:=\frac{0.05 \times 46 g}{0.95 \times 18}$

$:=\frac{2.3}{17.1}$ or $2.3: 17.1$

Now, from density, result can be drawn as following.

$: D=\frac{0.997 \mathrm{~g}}{1 c c}$

Multiplying both denominator and numerator by 1000 we have,

$: D=\frac{997 g}{1000 c c}$ 
By splitting the numerator in the ratio $2.3: 17.1$, we get the corresponding weights of solute and solvent. For that sum of the elements of the ratio is required i.e., $2.3+17.1=19.4$

:then $=\frac{\left\{\left(\frac{997}{19.4}\right) \times 2.3\right\} g+\left\{\left(\frac{997}{19.4}\right) \times 17.1\right\} g}{1000 \mathrm{ml}}$

$:=\frac{118.201 \mathrm{~g}+878.799 \mathrm{~g}}{1000 \mathrm{ml}}$

Transforming the numerator into moles by dividing them by their molar mass , we have,

$:=\frac{2.57 \mathrm{~mol}+48.82 \mathrm{~mol}}{1000 \mathrm{ml}}$

$:=\frac{2.57 \mathrm{~mol}}{1000 \mathrm{ml}}+\frac{48.82 \mathrm{~mol}}{1000 \mathrm{ml}}$

Taking only the required item we have,

$:=2.57 \mathrm{M}$

To find molality the known values 2.57 and 878.799 are taken and written as following.

$=\frac{2.57 \mathrm{~mol}}{878.799 \mathrm{~g}}$

To make the denominator equal to $1000 \mathrm{~g}$, both denominator and numerator are multiplied by the factor, $\frac{1000}{878.799}$

$=\frac{2.57 \mathrm{~mol} \times \frac{1000}{878.799}}{878.799 \mathrm{~g} \times \frac{1000}{878.799}}$

$=\frac{2.92 \mathrm{~mol}}{1000 \mathrm{~g}}$

$=2.92 \mathrm{~m}$

\section{Miscellaneous Problems}

9.01. The density of $3 \mathrm{M}$ solution of $\mathrm{NaCl}$ is $1.25 \mathrm{~g} \mathrm{~mL}^{-1}$ calculate the molality of the solution.(N.C.E.R.T.)[17] Opinion: This problem is non-pragmatic; hence solution to this problem is also impractical.

While solving this problem, it is said that "mass of $1 \mathrm{~L}$ of solution is $=1250 \mathrm{~g}$ "

and it is shown that mass of solvent which is water is said that "Mass of water in the solution $=1074.5 \mathrm{~g}$ "

When above two steps are analyzed, it is not possible to answer a question "How can $1 \mathrm{~L}$ of volume can contain $1074.5 \mathrm{~g}$ of water which is equal to $1074.5 \mathrm{ml}$ ?.Therefore the statement $1 \mathrm{~L}$ of solution contains 1074.5 $\mathrm{g}$ of solvent (water) is contradictory.

9.02. Convert $1.50 \mathrm{~km}^{3}$ of water into volumes in liters.[18]

Solution:

Given, $1.5 \mathrm{~km}^{3}$

It is required to convert to liters. Hence it can be written as following

$:=1.5(\mathrm{~km})^{3} \times \frac{L}{L}$

Kilo means thousand, Hence $1.5(\mathrm{~km})^{3} \times \frac{L}{L}=1.5 \times(1000 \mathrm{~m})^{3} \times \frac{L}{L}----(42)$

Since $1 \mathrm{~L}=1000 \mathrm{ml}=1000 \mathrm{~cm}^{3}=\frac{100 \mathrm{~cm}}{10} \times \frac{100 \mathrm{~cm}}{10} \times \frac{100 \mathrm{~cm}}{10}$

$:=\frac{m}{10} \times \frac{m}{10} \times \frac{m}{10}$

$:=\frac{m^{3}}{10^{3}}$

$:=(d m)^{3}$

$:=d m^{3}$

:Then (42) can be written as, $=1.5 \times(1000 \mathrm{~m})^{3} \times \frac{L}{\frac{m^{3}}{10^{3}}}$

$:=1.5 \times 10^{9} \times 10^{3} \times m^{3} \times \frac{L}{m^{3}}$

$:=1.5 \times 10^{12} \mathrm{~L}$

$:=1.5$ Trillion liters

9.03. A sample of $\mathrm{KClO}_{3}$ on decomposition yielded $448 \mathrm{ml}$ of oxygen gas at NTP, calculate

(i) Weight of oxygen produced 
(ii) Weight of $\mathrm{KClO}_{3}$ originally taken, and

(iii) Weight of $\mathrm{KCl}$ Produced

$(K=39, C l=35.5, O=16)$

Solution: By dimensional analysis.

Balanced chemical equation to the said reaction is

$: 2 \mathrm{KClO}_{3} \rightarrow 2 \mathrm{KCl}+3 \mathrm{O}_{2}$

Multiply throughout by 448 , which is the known volume.

$: 2 \times 448\left(\mathrm{KClO}_{3}\right) \rightarrow 2 \times 448(\mathrm{KCl})+3 \times 448\left(\mathrm{O}_{2}\right)$

Now, divide throughout by $3 \times 22400$, to convert them to molar volume.

$: \frac{2 \times 448}{3 \times 22400}\left(\mathrm{KClO}_{3}\right) \rightarrow \frac{2 \times 448}{3 \times 22400}(\mathrm{KCl})+\frac{3 \times 448}{3 \times 22400}\left(\mathrm{O}_{2}\right)$

$: 0.0133\left(\mathrm{KClO}_{3}\right) \rightarrow 0.0133(\mathrm{KCl})+0.02\left(\mathrm{O}_{2}\right)$

Multiplying by their respective molar mass we have,

$: 0.0133 \times 122.5\left(\mathrm{KClO}_{3}\right) \rightarrow 0.0133 \times 74.5(\mathrm{KCl})+0.02 \times 32\left(\mathrm{O}_{2}\right)$

$: 1.633 \mathrm{~g}\left(\mathrm{KClO}_{3}\right) \rightarrow 0.993 \mathrm{~g}(\mathrm{KCl})+0.64 \mathrm{~g}\left(\mathrm{O}_{2}\right)$

\section{Conclusion:}

Main intention is to maintain good continuity between the steps of solutions to problems of chemistry. Algebraic methods usually approach the result easily with least break, if some rules are followed.

\section{Online Journal}

\section{References:}

[1]. R. subramanya cheluvamba Hospital, Karnataka, Mysore, India, Improved and novel methods of Pharmaceutical calculations, FebMar, www.iosrphr.org, IOSR journal of Pharmacy.

Book

[2]. Dr. S.P. Jauhar, Modern's abc of Chemistry Class XI Part-I, Revised \& updated edition 2012-2013,(Modern Publishers, MDB House, Railway Road, Jalandar City India.

\section{Book Chapter}

[3]. Dr. S.P. Jauhar, Modern's abc of Chemistry Class XI Part-I (Modern Publishers, MDB House, Railway Road, Jalandar City India), Revised \& updated edition 2012-2013, P.27, Example 23.

[4]. Dr. S.P. Jauhar, Modern's abc of Chemistry Class XI Part-I,(Modern Publishers, MDB House, Railway Road, Jalandar City India), Revised \& updated edition 2012-2013, P.50.Example 61.

[5]. Dr. S.P. Jauhar, Modern's abc of Chemistry Class XI Part-I (Modern Publishers, MDB House, Railway Road, Jalandar City India), Revised \& updated edition 2012-2013,, P.52,Example 66.

[6]. Dr. S.P. Jauhar, Modern's abc of Chemistry Class XI Part-I (Modern Publishers, MDB House, Railway Road, Jalandar City India), Revised \& updated edition 2012-2013, P.26, Example 19.

[7]. Dr. S.P. Jauhar, Modern's abc of Chemistry Class XI Part-I (Modern Publishers, MDB House, Railway Road, Jalandar City India), Revised \& updated edition 2012-2013, P.27, Example 22

[8]. Dr. S.P. Jauhar, Modern's abc of Chemistry Class XI Part-I (Modern Publishers, MDB House, Railway Road, Jalandar City India), Revised \& updated edition 2012-2013, P.24,Section 2.

[9]. Dr. S.P. Jauhar, Modern's abc of Chemistry Class XI Part-I (Modern Publishers, MDB House, Railway Road, Jalandar City India), Revised \& updated edition 2012-2013, P.28,Example 24

[10]. Dr. S.P. Jauhar, Modern's abc of Chemistry Class XI Part-I (Modern Publishers, MDB House, Railway Road, Jalandar City India), Revised \& updated edition 2012-2013, P.43,Example47.

[11]. Dr. S.P. Jauhar, Modern's abc of Chemistry Class XI Part-I (Modern Publishers, MDB House, Railway Road, Jalandar City India) , Revised \& updated edition 2012-2013, P.389-390.

[12]. Dr. S.P. Jauhar, Modern's abc of Chemistry Class XI Part-I (Modern Publishers, MDB House, Railway Road, Jalandar City India), Revised \& updated edition 2012-2013, P.62. Example:88.

[13]. Dr. S.P. Jauhar, Modern's abc of Chemistry Class XI Part-I (Modern Publishers, MDB House, Railway Road, Jalandar City India), Revised \& updated edition 2012-2013, P.66,Example.97.

[14]. Dr. S.P. Jauhar, Modern's abc of Chemistry Class XI Part-I (Modern Publishers, MDB House, Railway Road, Jalandar City India), Revised \& updated edition 2012-2013, P.66,Example.98

[15]. Dr. S.P. Jauhar, Modern's abc of Chemistry Class XI Part-I (Modern Publishers, MDB House, Railway Road, Jalandar City India) ,Revised \& updated edition 2012-2013, P.71,Example.118

[16]. Dr. S.P. Jauhar, Modern's abc of Chemistry Class XI Part-I (Modern Publishers, MDB House, Railway Road, Jalandar City India), Revised \& updated edition 2012-2013, P.73,Example.125

[17]. Dr. S.P. Jauhar, Modern's abc of Chemistry Class XI Part-I (Modern Publishers, MDB House, Railway Road, Jalandar City India), Revised \& updated edition 2012-2013, P.72,Example.121

[18]. Dr. S.P. Jauhar, Modern's abc of Chemistry Class XI Part-I (Modern Publishers, MDB House, Railway Road, Jalandar City India), Revised \& updated edition 2012-2013, P.19. 44 th line.

[19]. R C Mukerjee,Bharathibhavan, Modern approach to chemical calculations (Publishers and Disributers,4271/3 Ansari road, Daryaganj new Delhi-110 002). seventh edition 2004, Revised print- 2011 Page No. 24.Example:4.

[20]. R C Mukerjee,Bharathibhavan, Modern approach to chemical calculations (Publishers and Disributers,4271/3 Ansari road, Daryaganj new Delhi-110 002). seventh edition 2004, Revised print- 2011 Page No. 364.Example:4. 